\title{
Analysis of tissue- and hormone-specific regulation of the human prolactin-inducible protein/gross cystic disease fluid protein-15 gene in transgenic mice
}

\section{Y Myal ${ }^{1}$, B Iwasiow, H Cosby, A Yarmill, A Blanchard, D Tsuyuki, A Fresnoza, M L Duckworth and R P C Shiu}

Departments of Pathology ${ }^{1}$ and Physiology, Faculty of Medicine, University of Manitoba, Winnipeg, Manitoba, Canada

(Requests for offprints should be addressed to Y Myal, Department of Pathology, Faculty of Medicine, University of Manitoba, 770 Bannatyne Ave., Winnipeg, Manitoba, Canada R3E 0W3)

\begin{abstract}
The human prolactin-inducible protein/gross cystic disease fluid protein-15 (PIP/GCDFP-15) gene is expressed in more than $90 \%$ of human breast cancer biopsies but not in the normal mammary gland. However, it is expressed in several normal human apocrine glands such as the lacrimal and salivary glands. In human breast cancer cell lines, the gene is regulated by a number of hormones including androgen and prolactin. It is not known whether gene expression in normal tissues is under similar hormonal control. To understand the mechanisms by which hormone- and tissue-specific expression of the human PIP/GCDFP-15 gene are regulated in vivo, we generated transgenic mice using a $13.7 \mathrm{~kb}$ genomic DNA fragment containing the entire $7 \mathrm{~kb}$ human gene, together with 2.9 kilobases of $5^{\prime}$ and $3 \cdot 8$ kilobases of $3^{\prime}$ flanking sequences. The human PIP/GCDFP-15 transgene was found to be
\end{abstract}

expressed in both the lacrimal and salivary glands but was not expressed in the mammary glands of transgenic mice. This tissue-specific pattern of the transgene expression in the mouse was very similar to that of the endogenous human PIP/GCDFP15 gene, and to the endogenous mouse gene. In the mouse salivary glands, the transgene expression was highest in the parotid, considerably less in the submaxillary (submandibular) and absent in the sublingual glands. In the mouse lacrimal gland, as in the human breast cancer cell lines, the human PIP/GCDFP-15 transgene was also up-regulated by androgen. These studies demonstrate that the human gene with its $6.3 \mathrm{~kb}$ flanking sequences is able to confer gene expression in vivo in a tissue-specific and hormone-responsive manner. Fournal of Molecular Endocrinology (1998) 21, 217-223

\section{INTRODUCTION}

The human prolactin-inducible protein/gross cystic disease fluid protein-15 (PIP/GCDFP-15) is a $14 \mathrm{kDa}$ protein first identified in human breast cancer cell lines (Shiu \& Iwasiow 1985) and in the fluid from benign gross cystic disease of the human breast (Haagensen \& Mazoujian 1986). The PIP/ GCDFP-15 gene expression has been detected in most ( 93\%) human breast tumor biopsies (Clark et al. 1996). PIP/GCDFP-15 has been used as a diagnostic marker for human breast cancer and for breast cancer progression (Mazoujian et al. 1983, 1989). In human breast cancer cell lines, the gene is regulated by a number of hormones including prolactin, estrogen, dexamethasone and cytokines, but is maximally up-regulated by androgen (Murphy et al. 1987, Simard et al. 1989, Blais et al. 1996). PIP/GCDFP-15 has also been detected in normal human tissues, particularly those apocrine in origin such as the Moll's gland of eyelids and the minor bronchial glands and in the secretions of the lacrimal and salivary glands; however, it is not expressed in the normal mammary gland (Mazoujian et al. 1983, Haagensen \& Mazoujian 1986, Murphy et al. 1987, Mazoujian \& Margolis 1988). It is not known whether the expression of the human PIP/GCDFP-15 gene in any of these normal tissues is under similar hormonal control as that observed in the human breast cancer cell lines.

The single copy human gene has previously been isolated and characterized (Myal et al. 1991). The 


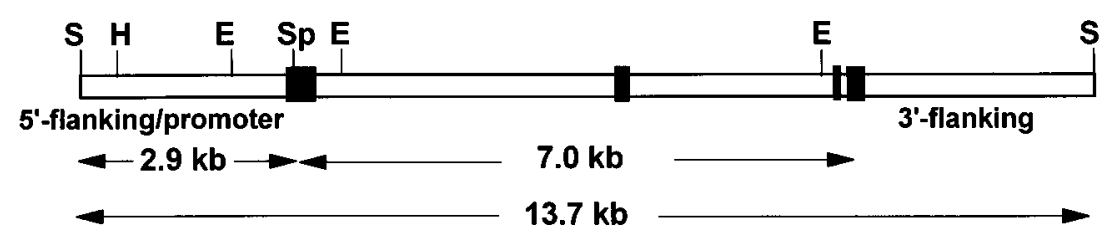

FIGURE 1. DNA construct used to generate transgenic mice. The human PIP/GCDFP-15 gene construct: the $13.7 \mathrm{~kb}$ clone contains the entire human PIP/GCDFP-15 gene (Myal et al. 1991) plus $6 \cdot 7 \mathrm{~kb}$ of $5^{\prime}$ and $3^{\prime}$ flanking sequences. The black boxes represent exons 1 to 4 . Abbreviations are as follows: S, SalI; H, HindIII; E, EcoRI; Sp, SphI; N, NcoI.

gene contains 4 exons and is $7 \mathrm{~kb}$ long. Despite extensive characterization of the PIP/GCDFP15 gene and the encoded protein by us and others, the biological role of PIP/GCDFP-15 still remains unknown. However, recent data (Autiero et al. 1997) suggest that PIP/GCDFP-15, also named gp17, may function as an immunomodulatory CD4 binding factor. As of date, the hormonal regulation and tissue-specific gene expression in vivo have not been addressed.

A cDNA of the mouse homolog of human PIP/GCDFP-15, the mouse submaxillary gland protein, mSMGP, has been isolated and characterized (Windass et al. 1984, Myal et al. 1994). It has $58 \%$ sequence identity with the human PIP/ GCDFP-15 (Myal et al. 1991). This cDNA was used to study the SMGP gene expression in two rodent species, mouse and rat. In the rat, the SMGP gene was expressed in the salivary and lacrimal glands; in the latter tissue its expression was inhibited by androgen (Myal et al. 1994). In the mouse, the gene was also expressed in the salivary and lacrimal glands but was not regulated by androgen (Windass et al. 1984; present study). Despite the $58 \%$ sequence homology that exists between mouse SMGP and human PIP/ GCDFP-15 cDNAs, they do not cross hybridize (Murphy et al. 1987). In addition, unlike the human PIP/GCDFP-15 gene which was highly expressed in human breast cancer and benign breast cystic diseases, the rodent SMGP gene was not expressed in rat and mouse mammary tumors (Myal et al. 1994). Thus, for all the above reasons these rodent genes are not suitable models for studying hormonal and tissue regulation of the human gene.

In the present study, we generated transgenic mice carrying the entire PIP/GCDFP-15 gene in order to address tissue- and hormone-specific gene expression. The tissue-specific pattern of expression of the human PIP/GCDFP-15 transgene was found to be similar to that of the endogenous gene in humans. Further, the up-regulation of the transgene by androgen was consistent with the hormonal regulation of the gene in human breast cancer cell lines.

\section{MATERIALS AND METHODS}

\section{Transgenic animals}

A $13.7 \mathrm{~kb}$ genomic DNA fragment containing the entire $7 \mathrm{~kb}$ PIP/GCDFP-15 gene plus $2.9 \mathrm{~kb}$ of $5^{\prime}$ and $3.8 \mathrm{~kb}$ of $3^{\prime}$ flanking DNA sequences (Fig. 1) was used for pronuclear microinjections into one-cell C57BL/6J $\times$ SJL mouse embryos (DNX Transgenic Services, Princeton, NJ, USA). Breeding of transgenic mice was carried out at the University of Manitoba animal facility. Mice carrying the transgene were identified by Southern blot analysis (Southern 1975) of EcoRI-digested genomic DNA extracted from tail biopsies (Hogan et al. 1986) using a nick-translated PIP/GCDFP-15 cDNA insert. Upon backcrossing the founder animal to $\mathrm{C} 57 \mathrm{BL} / 6 \mathrm{~J} \times \mathrm{SJL}$ mice, two transgene insertions segregated. Inbred sublines (tgd1 and tgd1.5) with stable transgene transmission patterns were generated by further backcrossing to C57BL/ $6 \mathrm{~J} \times \mathrm{SJL}$ mice. From this point on, offspring were bred with CD1 mice. Heterozygous siblings were interbred to generate homozygous animals which were used in all experiments.

\section{Hormone treatment}

Hormones, purchased from Innovative Research of America (Sarasota, FL, USA), were administered in the form of a continuous release pellet ( $5 \alpha$-dihydrotestosterone, $5 \mathrm{mg} / \mathrm{pellet}$; retinoic acid, $5 \mathrm{mg} /$ pellet; dexamethasone, $2.5 \mathrm{mg} /$ pellet; $17 \beta$ estradiol, $5 \mathrm{mg} /$ pellet; medroxyprogesterone acetate, $25 \mathrm{mg} /$ pellet). The pellets contained steroids with a carrier-binder composed of cholesterol-methyl cellulose- $\alpha$-lactose. Three-month-old male and 
A

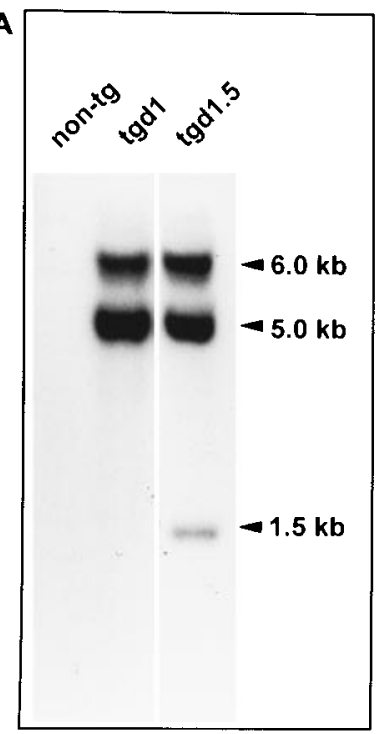

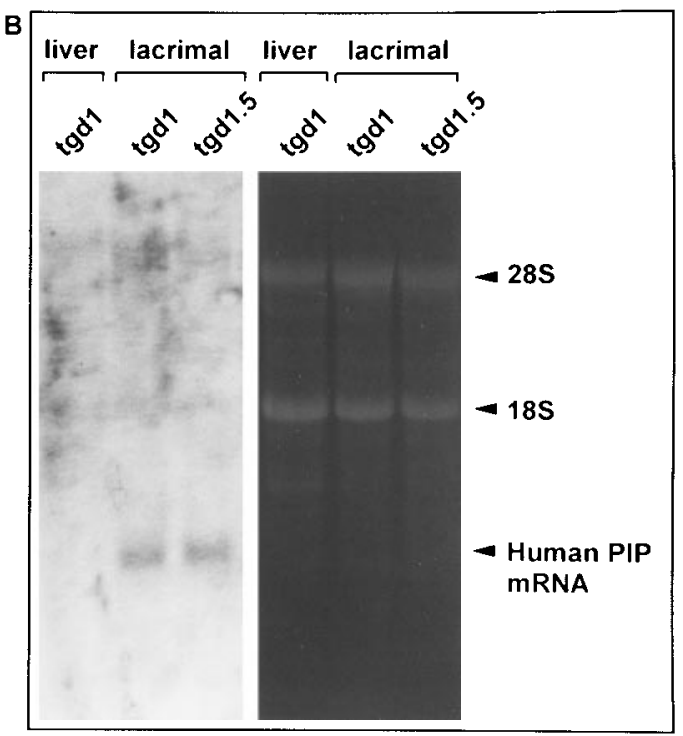

FIGURE 2. Southern blot analysis and transgene expression in mice. (A) Ten micrograms mouse tail genomic DNA were digested with the EcoRI restriction enzyme, separated on a $0 \cdot 8 \%$ agarose gel and transferred to nitrocellulose filter. Nick-translated ${ }^{32}$ P-labeled human PIP/GCDFP-15 cDNA insert was used as a probe. Left lane, genomic DNA from a non-transgenic (non-tg) mouse. Middle lane, genomic DNA from the transgenic mouse line tgd1. Right lane, genomic DNA from the transgenic mouse line tgd1.5. A $1.5 \mathrm{~kb}$ band is absent in the middle lane. (B) Northern blot analysis (in the first three lanes) showing the human PIP/GCDFP-15 transgene expression in the tgd1.5 and tgd1 lines. Blots were probed with the ${ }^{32} \mathrm{P}$-labeled human PIP/GCDFP-15 cDNA insert. Each lane contained $40 \mu \mathrm{g}$ total RNA. The transgene was expressed in the lacrimal gland but not in the liver. Ethidium bromide staining of $28 \mathrm{~S}$ and $18 \mathrm{~S}$ ribosomal RNA is shown in the last three lanes.

female transgenic mice were implanted subcutaneously with pellets containing either placebo or hormones 10 days after surgery (ovariectomy or castration). Three weeks later, the animals were anaesthetized with ether and killed. Tissues were dissected and immediately frozen in liquid nitrogen and later stored at $-70{ }^{\circ} \mathrm{C}$ until needed for RNA isolation.

\section{RNA isolation and Northern blot analysis}

Total RNA was isolated from mouse tissue by the method of Chirgwin et al. (1979). Northern blot analysis was performed as previously described (Myal et al. 1996) using $40 \mu \mathrm{g}$ total RNA from each sample. Hybridization was carried out with the ${ }^{32} \mathrm{P}$-labeled human PIP/GCDFP-15 cDNA probe and blots were exposed to X-ray films. Band intensities were quantitated by densitometry using a Microcomputer Imaging Device (Image Res. Inc., Ontario, Canada) and normalized against ethidium bromide-stained 28S ribosomal RNA.

\section{RESULTS}

\section{Generation of human PIP/GCDFP-15 transgenic mice}

To study hormone- and tissue-specific regulation of the human PIP/GCDFP-15 gene, transgenic mouse lines carrying the entire human PIP/GCDFP-15 gene (Fig. 1) were generated. Southern blot analysis of tail genomic DNAs isolated from the two transgenic lines is shown in Fig. 2A. As expected, the labeled human PIP/GCDFP-15 cDNA probe did not cross hybridize with the endogenous mouse SMGP gene (Fig. 2A, left lane). In the middle and right lanes, the hybridization patterns of the EcoRI-digested genomic DNA isolated from the transgenic lines tgd 1 and tgd1.5 are shown. A $1.5 \mathrm{~kb}$ fragment observed in tgd 1.5 lane 3 is absent in tgd1 (middle lane), suggesting a disruption of the 5' EcoRI restriction site (Myal et al. 1991) within the PIP/GCDFP-15 transgene of the tgd1 mice. However, the mutation at this site is benign since both transgenic lines expressed the human 


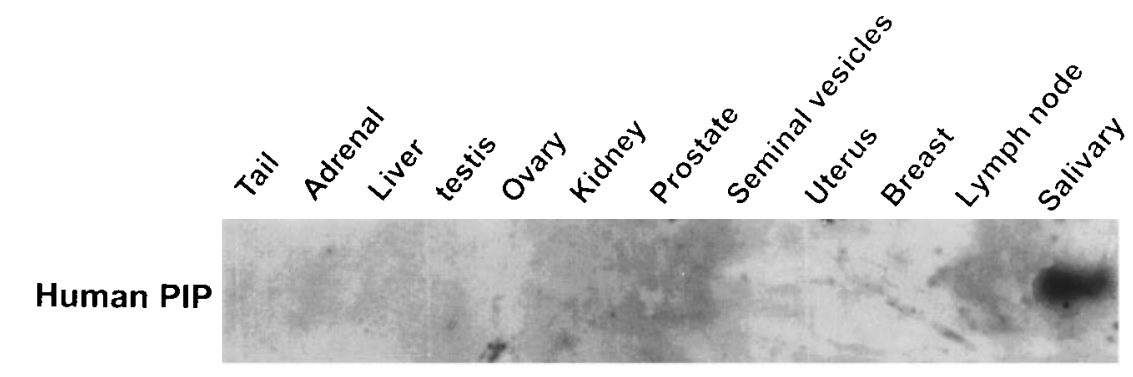

\section{Mouse SMGP}

FIGURE 3. Tissue-specific expression of the human PIP/GCDFP-15 gene in transgenic mice. Northern blot analysis was carried out using $40 \mu \mathrm{g}$ total RNA from tissues dissected from transgenic mice. Human PIP/GCDFP-15 transgene expression was detected in the salivary glands and the lacrimal gland (shown in Figs 2 and 4). All other tissues examined were negative for the human PIP/GCDFP-15 gene expression.

PIP/GCDFP-15 transcript at the same level (Fig. 2B) and in the same tissue-specific manner. Therefore, although both lines were studied, only the results obtained from one of these lines (the $\operatorname{tgd} 1 \cdot 5)$ are shown in the following studies.

\section{Tissue-specific expression of the human PIP/GCDFP-15 transgene}

To determine the tissue specificity of the human PIP/GCDFP-15 transgene expression, male and female mice were killed at 3 months of age and total RNA extracted from several tissues as described in Materials and Methods. The human PIP/ GCDFP-15 transcript was detected in the salivary and lacrimal glands of the transgenic mice (Figs 3 and 4). All other tissues, including the mammary gland (Fig. 3), were negative for the transgene expression. Therefore, the tissue-specific expression of the transgene was identical to that of the endogenous mouse SMGP gene. In addition, different levels of transgene expression were observed among the major salivary glands. The parotid gland exhibited the highest level of transgene expression (Fig. 4) and the sublingual gland did not contain any detectable transgene expression.

\section{Hormonal regulation of the human PIP/GCDFP-15 transgene}

To investigate the regulation of the transgene by hormones, ovariectomized and castrated transgenic mice were supplemented with exogenous hormonal

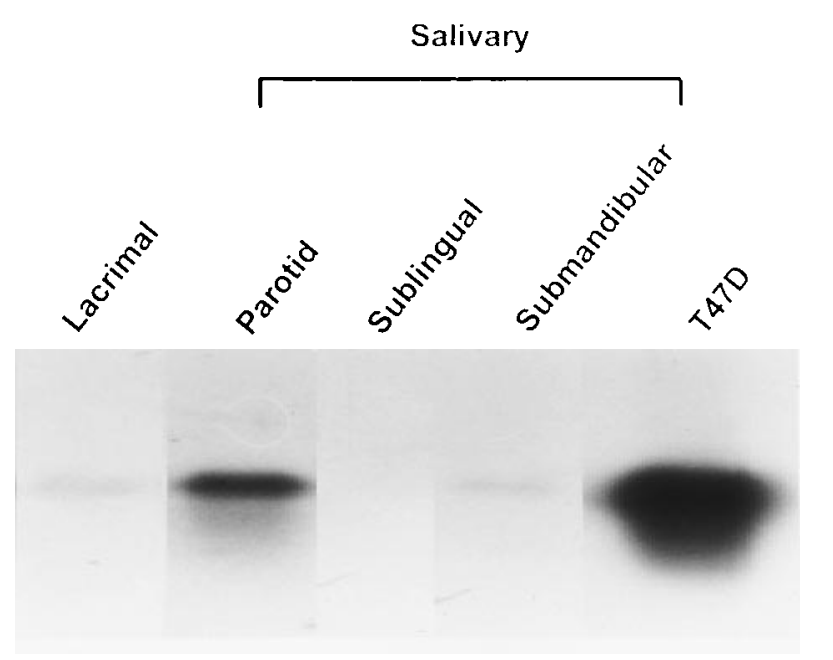

FIGURE 4. Human PIP/GCDFP-15 transgene expression is highest in the parotid gland. Forty micrograms total RNA were used for Northern blot analysis. Results show varying levels of human PIP/GCDFP-15 gene expression in the lacrimal and salivary glands with the highest level of expression in the parotid gland. Transgene expression was not detectable in the sublingual gland. Five micrograms total RNA from the human breast cancer cell line T47D were used as a positive control.

pellets (see Materials and Methods). Only in the lacrimal gland of both male (Fig. 5) and female mice (not shown) did androgen stimulate (4-fold) human PIP/GCDFP-15 transgene expression. In contrast, retinoic acid, dexamethasone, $17 \beta$-estradiol, and medroxyprogesterone acetate did not have any effect 


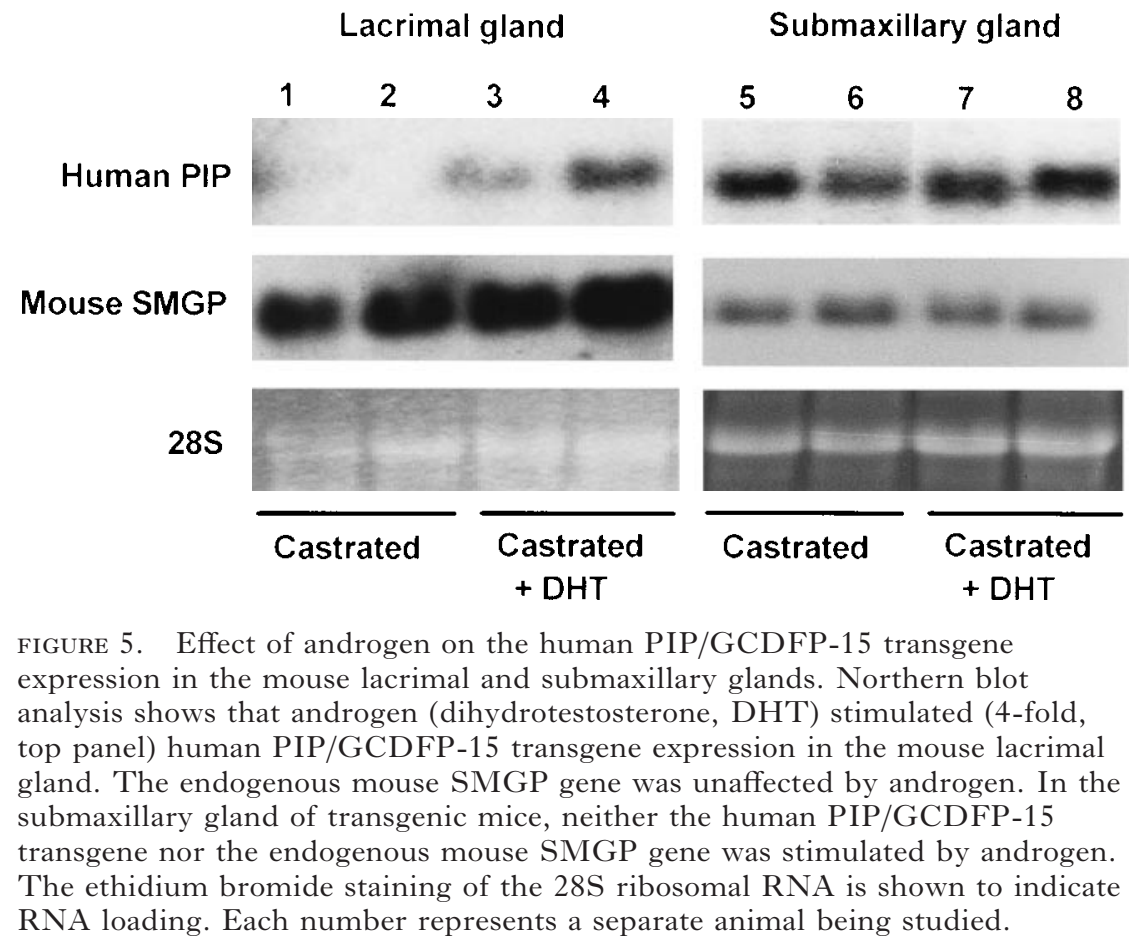

on the transgene expression (data not shown). The endogenous mouse SMGP gene expression was not regulated by androgen (Fig. 5) in the lacrimal glands of transgenic animals. In the submaxillary gland, all hormones tested failed to influence the expression of both the PIP/GCDFP-15 transgene and the endogenous mouse SMGP gene.

\section{DISCUSSION}

The human PIP/GCDFP-15 gene is regulated both positively and negatively by a variety of steroid and peptide hormones in human breast cancer cell lines in culture. In particular, androgens are potent stimulators of the human PIP/GCDFP-15 gene expression (Murphy et al. 1987, Simard et al. 1989, Blais et al. 1996). However, the hormonal regulation of the human PIP/GCDFP-15 gene in normal tissues in vivo has not previously been investigated due to the lack of an appropriate model system. In view of the fact that SMGP (the rodent homolog of PIP/GCDFP-15) was inhibited by androgen (Myal et al. 1994) in the rat, and was unaffected by hormones in the mouse (Fig. 5), both rodent genes are unsuitable models for studying tissue and hormonal regulation of the human gene. In this study, transgenic mice bearing the human PIP/
GCDFP-15 gene were generated to examine tissue and hormone specificity of gene expression.

Southern blot analysis of genomic DNA showed that the hybridization patterns of the two transgenic lines obtained differed by one band. The expected EcoRI restriction digestion pattern of the unaltered human gene was observed with the tgd1 5 genomic DNA (Myal et al. 1991). The tgd1 genomic DNA pattern suggested a possible mutation in an EcoRI site in the $5^{\prime}$ region of the gene. In both lines, however, the transgene was stably transmitted and transgene expression was similar in intensity and specificity. Therefore, the possibility of a deletion or rearrangement at the $5^{\prime}$ EcoRI site of the PIP/GCDFP-15 transgene can be ruled out. The two different hybridization patterns observed may simply be attributed to a base mutation at the $5^{\prime}$ EcoRI site.

Tissue specificity for the PIP/GCDFP-15 gene expression has been determined for the most part in humans by immunohistochemistry studies (Haagensen \& Mazoujian 1986) and Northern blot analysis (Murphy et al. 1987). The isolation of the human PIP/GCDFP-15 gene has allowed us to examine whether the $13.7 \mathrm{~kb}$ genomic fragment was able to confer tissue-specific expression in transgenic mice. Northern blot analysis revealed that the human transgene was expressed only in the mouse 
lacrimal and salivary (parotid and submaxillary) glands. These results are consistent with the previous findings that, in both human and rodents (rat and mice), PIP/GCDFP-15 and SMGP were localized in the lacrimal and salivary glands. We further examined transgene expression in the salivary glands and determined that the maximum level of expression was in the parotid glands. All the above results demonstrate that the $13.7 \mathrm{~kb}$ transgene was indeed functional in vivo and contained sufficient information to direct the tissue-specific expression of the human PIP/GCDFP-15 gene in the lacrimal and salivary glands.

The transgenic mouse mammary gland was negative for the human PIP/GCDFP-15 gene expression. This result was not surprising since in both humans (Mazoujian et al. 1983, Haagensen \& Mazoujian 1986, Murphy et al. 1987) and mice (Myal et al. 1994) the endogenous genes are not expressed in the normal mammary gland. Benign and malignant transformation of the human breast result in the ectopic expression of the PIP/ GCDFP-15 gene (Shiu \& Iwasiow 1985, Haagensen \& Mazoujian 1986). As a first step towards understanding the consequences of ectopic expression of PIP/GCDFP-15 in the mammary gland, we have generated transgenic mouse models which harbor a mouse mammary tumor virus long terminal repeat (MMTV-LTR) PIP/GCDFP-15 fusion gene (Myal et al. 1998). These transgenic mice express high levels of the PIP/GCDFP-15 in their mammary gland (Myal et al. 1998).

Hormonal regulation of the human PIP/ GCDFP-15 gene has been extensively studied in human breast cancer cell lines. The most potent stimulator of the human PIP/GCDFP-15 gene is androgen (dihydrotestosterone, DHT) whereas estrogen specifically inhibits the androgen induction of gene expression in these human breast tumor cell lines (Murphy et al. 1987, Simard et al. 1989, Blais et al. 1996). In the transgenic mouse salivary gland neither androgen nor any of the hormones studied (retinoic acid, dexamethasone, estrogen, medroxyprogesterone acetate), had any effect on the transgene expression. This observation is consistent with the lack of hormonal regulation of the rodent SMGP gene in this gland, as previously shown in rats (Myal et al. 1994) and now in mice. Through in situ nucleic acid hybridization studies, we earlier established that the expression of the SMGP gene in the salivary glands of rats was confined to serous acinar cells and not ductal cells (Myal et al. 1994). In human salivary glands only these acinar cells are known to contain immunoreactive PIP/GCDFP-15 (Haagensen \& Mazoujian 1986). However, while ductal cells contain androgen receptors, acinar cells do not. Therefore, it is not surprising that the transgene, which is expressed in the acinar cells, does not respond to androgen, resulting in an absence of hormonal regulation of the transgene in the mouse submaxillary gland.

In the lacrimal gland of transgenic animals, however, the influence of androgen on the transgene expression was evident. As in the human breast cancer cell lines (Murphy et al. 1987), the PIP/GCDFP-15 transgene expression (Fig. 5) was up-regulated by androgen. Interestingly, in the same tissue, the endogenous mouse SMGP gene expression was unaffected by androgen. Thus, the lack of response to androgen by the endogenous mouse gene (SMGP) may suggest that the mouse gene either lacks an androgen responsive element or contains a suppressor sequence which overrides the androgen response. In addition, we have reported that in the rat, the SMGP gene was suppressed by androgen in the lacrimal gland (Myal et al. 1994). It therefore appears that the mechanism for hormonal responsiveness in vivo may indeed be complex and may involve numerous parameters such as gene structure differences, and species- and tissuespecific transacting factors. The fact that the expression of the human PIP/GCDFP-15 transgene was regulated differently by androgen in two different tissues (salivary and lacrimal glands) in the transgenic mice underscores the importance of tissue-specific transacting factors. Therefore, the human PIP/GCDFP-15 transgenic mouse model may be a useful tool for studying both hormonal and tissue-specific regulatory elements in the lacrimal and salivary glands.

Our results have demonstrated that the $13.7 \mathrm{~kb}$ human genomic DNA containing the PIP/ GCDFP-15 gene and its flanking sequences must contain functional tissue- and hormone-specific regulatory elements. We further attempted to define regions within the gene which conferred tissue- and hormone-specific expression in vivo, by generating, in our laboratory, transgenic mice carrying a human PIP-CAT fusion gene consisting of a $2.9 \mathrm{~kb} \mathrm{5}$ flanking/promoter human PIP/GCDFP-15 gene sequence fused to the bacterial chloramphenicol acetyltransferase (CAT) gene (D Tsuyuki, Y Myal, H Cosby \& R Shiu, unpublished observations). We were unable to detect CAT gene expression in these transgenic mice, suggesting that the $2.9 \mathrm{~kb} \mathrm{5}$ flanking PIP/GCDFP-15 gene sequence alone was insufficient to confer gene expression in vivo. This finding suggests that other regions such as the $3^{\prime}$ flanking sequences and the introns are needed for PIP/GCDFP-15 gene expression in vivo.

In this study we have established human PIP/GCDFP-15 transgenic mice to examine 
hormone and tissue specificity of gene expression. This transgenic mouse model may be particularly useful for studying hormonal and tissue-specific regulatory elements in the lacrimal and salivary glands.

\section{ACKNOWLEDGEMENTS}

The authors would like to thank June McDougald for assistance with typing the manuscript. This work was supported by a grant from the Medical Research Council of Canada.

\section{REFERENCES}

Autiero M, Gaubin M, Mani J-C, Castejon C, Martin M, El Marhomy S, Guardiola J \& Piatier-Tonneau D 1997 Surface plasmon resonance analysis of gp17, a natural CD4 ligand from human seminal plasma inhibiting human immunodeficiency virus type-1 gp120-mediated syncytium formation. European Fournal of Biochemistry 245 208-213.

Blais Y, Gingras S, Haagensen DE, Labrie F \& Simard J 1996 Interleukin-4 and interleukin-13 inhibit estrogen-induced breast cancer cell proliferation and stimulate GCDFP-15 expression in human breast cancer cells. Molecular and Cellular Endocrinology 121 11-18.

Chirgwin JM, Przybyla A, MacDonald J \& Rutter W 1979 Isolation of biologically active ribonucleic acid from sources enriched in ribonuclease. Biochemistry 18 5294-5299.

Clark JW, Shiu RPC, Orr FW \& Watson PH 1996 Reverse transcription polymerase chain reaction assay for prolactininducible protein gene expression to detect human breast cancer micrometastasis. Annual Meeting of the American Association for Cancer Research, Washington, DC $\mathbf{7 8}$ Abstract no. 595.

Haagensen DE Jr \& Mazoujian G 1986 Biochemistry and immunohistochemistry of fluid proteins of the breast in gross cystic disease. In Diseases of the Breast, edn 3, pp 474-500. Ed CD Haagensen. Philadelphia: WB Saunders Co.

Hogan BF, Constantini F \& Lacy E 1986 Manipulating the Mouse Embryo: a Laboratory Manual, pp 190-195. Cold Spring Harbor, New York: Cold Spring Harbor Laboratory. Mazoujian G \& Margolis R 1988 Immunohistochemistry of gross cystic disease fluid protein (GCDFP-15) in 65 benign sweat gland tumors of the skin. American Fournal of Dermatology and Pathology 10 28-35.
Mazoujian G, Pinkus GS, Davis S \& Haagensen DE Jr 1983 Immunohistochemistry of a breast gross cystic disease fluid protein (GCDFP-15): marker of apocrine epithelium and breast carcinomas with apocrine features. American Fournal of Pathology 110 105-111.

Mazoujian G, Bodian C \& Haagensen DE 1989 Expression of GCDFP-15 in breast carcinomas. Relationship to pathological and clinical factors. Cancer 63 2156-2161.

Murphy LC, Tsuyuki D, Myal Y \& Shiu RP 1987 Isolation and sequencing of a cDNA clone for a prolactin-inducible protein (PIP). Regulation of PIP gene expression in the human breast cancer cell line, T-47D. Fournal of Biological Chemistry 262 15236-15241.

Myal Y, Robinson DB, Iwasiow B, Tsuyuki D, Wong P \& Shiu RPC 1991 The prolactin-inducible protein (PIP/GCDFP-15) gene: cloning, structure and regulation. Molecular and Cellular Endocrinology 80 165-175.

Myal Y, Iwasiow B, Yarmill A, Harrison E, Paterson JA \& Shiu RPC 1994 Tissue-specific androgen-inhibited gene expression of a submaxillary gland protein, a rodent homolog of the human prolactin-inducible protein/GCDFP-15 gene. Endocrinology 135 1605-1610.

Myal Y, Iwasiow B, Yarmill A \& Shiu RPC 1996 A new member of the hormonally regulated rodent submaxillary gland glycoprotein gene family: cDNA cloning and tissue-specific expression. Molecular and Cellular Endocrinology $120133-138$.

Myal Y, Iwasiow B, Cosby H, Yarmill A \& Shiu RPC 1998 Mouse mammary tumor virus (MMTV)-targeted gene expression of the human gross cystic disease fluid protein-15/prolactin inducible protein (GCDFP-15/PIP) in the mammary gland of transgenic mice. Transgenics 2 $327-332$.

Shiu RPC \& Iwasiow BM 1985 Prolactin-inducible proteins in human breast cancer cells. Fournal of Biological Chemistry 260 11307-11313.

Simard J, Hatton AC, Labrie C, Dauvois S, Zhao HF, Haagensen DE \& Labrie F 1989 Inhibitory effect of estrogens on GCDFP-15 mRNA levels and secretion in ZR-75-1 human breast cancer cells. Molecular Endocrinology 3 694-702.

Southern E 1975 Detection of specific sequence among DNA fragments separated by gel electrophoresis. Fournal of Molecular Biology 98 503-517.

Windass JD, Mullins JJ, Beecraft LJ, George H, Meacock PA, Williams RRG \& Brammer WJ 1984 Molecular cloning of cDNAs from androgen-independent mRNA species of DBA/2 mouse submaxillary glands. Nucleic Acids Research 12 1361-1376.

RECEIVED 15 December 1997 